\title{
Don't change the guidelines yet, randomized data on surgical left atrial appendage closure is on the horizon
}

John J. Squiers, MD, ${ }^{a}$ and J. Michael DiMaio, $\mathrm{MD}^{\mathrm{b}}$

\footnotetext{
From the ${ }^{\mathrm{a}}$ Department of Surgery, Baylor University Medical Center, Dallas, Tex; and ${ }^{\mathrm{b}}$ Department of Cardiothoracic Surgery, The Heart Hospital Baylor Plano, Plano, Tex.

Disclosures: Authors have nothing to disclose with regard to commercial support.

Received for publication March 30, 2018; accepted for publication April 5, 2018; available ahead of print May 18 2018.

Address for reprints: J. Michael DiMaio, MD, The Heart Hospital Baylor Plano, 1100 Allied Drive, Plano, TX 75093 (E-mail: jmdimaio@yahoo.com).

J Thorac Cardiovasc Surg 2018;156:1081-2

$0022-5223 / \$ 36.00$

Copyright (c) 2018 by The American Association for Thoracic Surgery

https://doi.org/10.1016/j.jtcvs.2018.04.011
}

Atrial fibrillation (AF) remains the most common rhythm disorder of clinical significance ${ }^{1}$ and one of the leading causes of cardiogenic ischemic events. ${ }^{2}$ The most common anatomic source of thrombus in patients with AF is the left atrial appendage (LAA). ${ }^{3}$ Greater than $10 \%$ of patients undergoing cardiac surgery have been diagnosed with AF preoperatively, ${ }^{4}$ so surgeons have naturally had long-standing interest in LAA interventions that might reduce the risk of stroke. Unfortunately, the data currently available to support routine surgical LAA occlusion present a mixed picture, even to the most optimistic surgeon. ${ }^{5-7}$

Ando and colleagues ${ }^{8}$ are to be congratulated on their exhaustive systematic review of the literature to gather the best data on surgical LAA occlusion and to determine its short-term (30-day or in-hospital) effectiveness regarding prevention of mortality and stroke via meta-analysis. The authors identified 3 randomized controlled trials (RCTs) and 4 adjusted retrospective studies for inclusion, although only 3 studies (totaling 2464 patients) contributed to the mortality end point and 6 studies (3846 patients) contributed to the stroke end point because of limitations in data extraction from the original publications. The metaanalysis demonstrated that surgical LAA occlusion was associated with a reduction in mortality (odds ratio, $0.384 ; 95 \%$ confidence interval, 0.233-0.631) and stroke (odds ratio, 0.622; 95\% confidence interval, 0.388-0.988), with further subanalyses identifying a particularly strong benefit in patients with preoperative AF and possibly with those undergoing valve interventions as well.

Should not such clear-cut results have the guideline writers running to their desks with pencils sharpened to draft an update regarding surgical LAA closure? Not so fast because, despite its many strengths, this analysis has several important limitations: (1) follow-up limited to 30-day/ in-hospital events; (2) a heterogeneous study population; and (3) inclusion of, we estimate, at least a dozen variations on surgical LAA closure (endocardial and epicardial suture exclusion/excision, stapler exclusion/excision with

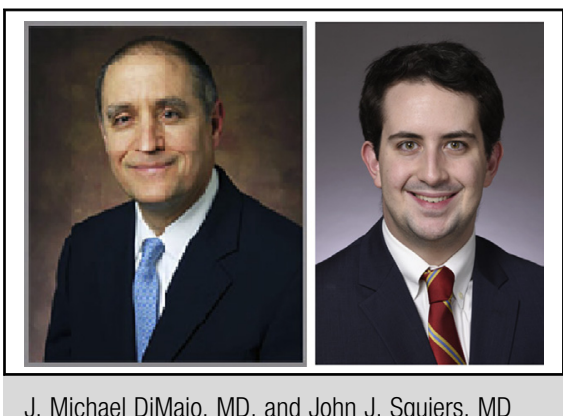

J. Michael DiMaio, MD, and John J. Squiers, MD

Central Message

This meta-analysis demonstrates clear shortterm benefits to surgical LAA closure. Ongoing RCTs will most likely determine the future of clinical practice.

See Article page 1071.

or without suture reinforcement, snares and suture loops, as well as epicardial exclusion clips and other devices), most of which are associated with high failure rates when closely studied via postoperative imaging over time. ${ }^{7,9}$ Thus, despite the statistical and clinical significance of their findings, Ando and colleagues ${ }^{8}$ wisely tempered their conclusion, stating only that surgical LAA closure "should be considered at the time of open cardiac surgery." Importantly, they did not make an explicit recommendation for this practice, even in patients with preoperative AF.

In the meantime, 2 important RCTs evaluating the effectiveness of surgical LAA closure are currently ongoing, with results expected around the year 2020. The Left Atrial Appendage Occlusion Study III seeks to randomize 4700 patients with AF undergoing cardiac surgery to surgical LAA occlusion or no occlusion using LAA amputation with double-layer linear suture closure (preferred), staplers, or other Food and Drug Administration-approved devices. ${ }^{10}$ The AtriClip Left Atrial Appendage Exclusion Concomitant to Structural Heart Procedures trial aims to randomize 2000 patients without preoperative AF but at high risk to develop postoperative $\mathrm{AF}$ based on a $\mathrm{CHA}_{2} \mathrm{DS}_{2}$-VASc 2 or greater to occlusion with the AtriClip device (AtriCure, Inc, Mason, Ohio) or no occlusion. ${ }^{11}$ The results of these investigations do have the potential to define clinical practice guidelines after they are presented, given 
that both RCTs are enrolling substantial numbers of patients from well-defined populations and will report long-term ( $>4$ years) follow-up data.

Meta-analyses often provide powerful summary data in an easily interpretable format that can be very influential in the development of clinical practice guidelines. In this case, however, Ando and colleagues ${ }^{8}$ concluded, and we agree, that their article should serve to encourage prospective investigations on surgical LAA occlusion. Fortunately, large-scale RCT data are fast approaching on the horizon.

\section{References}

1. Go AS, Mozaffarian D, Roger VL, Benjamin EJ, Berry JD, Blaha MJ, et al. Heart disease and stroke statistics-2014 update: a report from the American Heart Association. Circulation. 2014;129:e28-292.

2. Wolf PA, Abbott RD, Kannel WB. Atrial fibrillation as an independent risk factor for stroke: the Framingham study. Stroke. 1991;22:983-8.

3. Blackshear JL, Odell JA. Appendage obliteration to reduce stroke in cardiac surgical patients with atrial fibrillation. Ann Thorac Surg. 1996;61:755-9.
4. Whitlock RP, Vincent J, Blackall MH, Hirsh J, Fremes S, Novick R, et al. Left atrial appendage occlusion study II (LAAOS II). Can J Cardiol. 2013;1443-7.

5. Friedman DJ, Piccini JP, Wang T, Zheng J, Malaisrie SC, Holmes DR, et al. Association between left atrial appendage occlusion and readmission for thromboembolism among patients with atrial fibrillation undergoing concomitant cardiac surgery. JAMA. 2018;319:365-74.

6. Gillinov M. The left atrial appendage: won't get fooled again. J Thorac Cardiovasc Surg. 2016;152:1081-2.

7. Squiers JJ, Edgerton JR. Surgical closure of the left atrial appendage: the past, the present, the future. J Atr Fibrillation. 2018;10:1-5.

8. Ando M, Funamoto M, Camereon DE, Sundt TM. Concomitant surgical closure of the left atrial appendage: a systematic review and meta-analysis. JThorac Cardiovasc Surg. 2018;156:1071-80.e2.

9. Lee RL, Vassallo P, Kruse J, Malaisrie SC, Rigolin V, Andrei AC, et al. A randomized, prospective pilot comparisons of three atrial appendage elimination techniques: internal ligation, stapled excision, and surgical excision. J Thorac Cardiovasc Surg. 2016;152:1075-80.

10. Whitlock R, Healey J, Vincent J, Brady K, Teoh K, Royse A, et al. Rationale and design of the left atrial appendage occlusion study (LAAOS) III. Ann Cardiothorac Surg. 2014;3:45-54.

11. AtriCure, Inc. AtriClip left atrial appendage exclusion concomitant to structural heart procedures (ATLAS). Available at: https://clinicaltrials.gov/ct2/show/ study/NCT02701062?show_locs=Y\#locn. Accessed March 29, 2018. 